\title{
Research on Exhaust Emissions in Dynamic Operating States of a Combustion Engine in a Real Driving Emissions Test
}

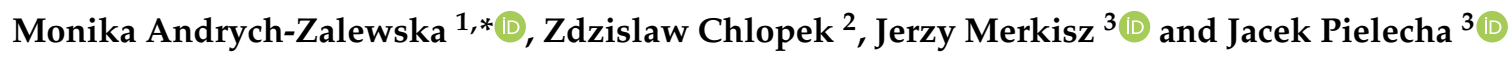 \\ 1 Faculty of Mechanical Engineering, Wroclaw University of Science and Technology, Wybrzeze \\ Wyspianskiego 27, 50-370 Wroclaw, Poland \\ 2 Faculty of Automotive and Construction Machinery Engineering, Warsaw University of Technology, \\ Narbutta 84, 02-524 Warsaw, Poland; zdzislaw.chlopek@pw.edu.pl \\ 3 Faculty of Civil and Transport Engineering, Poznan University of Technology, pl. M. Sklodowskiej-Curie 5, \\ 60-965 Poznan, Poland; jerzy.merkisz@put.poznan.pl (J.M.); jacek.pielecha@put.poznan.pl (J.P.) \\ * Correspondence: monika.andrych@pwr.edu.pl; Tel.: +48-71-347-7918
}

check for updates

Citation: Andrych-Zalewska, M.; Chlopek, Z.; Merkisz, J.; Pielecha, J. Research on Exhaust Emissions in Dynamic Operating States of a Combustion Engine in a Real Driving Emissions Test. Energies 2021, 14, 5684. https://doi.org/10.3390/ en14185684

Academic Editors: Zissis Samaras and Attilio Converti

Received: 9 August 2021

Accepted: 7 September 2021

Published: 9 September 2021

Publisher's Note: MDPI stays neutral with regard to jurisdictional claims in published maps and institutional affiliations.

Copyright: (c) 2021 by the authors. Licensee MDPI, Basel, Switzerland. This article is an open access article distributed under the terms and conditions of the Creative Commons Attribution (CC BY) license (https:/ / creativecommons.org/licenses/by/ $4.0 /)$.

\begin{abstract}
The paper describes the method of investigations of exhaust emissions from a combustion engine under operation classified in terms of its dynamic states. In this paper, the engine operating states are determined through the vehicle driving under actual traffic conditions in the RDE (Real Driving Emissions) test. Based on the recorded tracings of the vehicle velocity, the engine states were classified as static for the acceleration of the absolute value lower than the adopted classification limit. Besides, the authors analyzed the engine operating states for the positive as well as negative acceleration. For the adopted engine operating states, zero-dimensional characteristics of the emission intensity for individual exhaust components were determined (average value, coefficient of variation). The influence of the analyzed operating states on the emission of individual exhaust components was assessed. The greatest increase in the intensity of the emission of nitrogen oxides was observed for the positive vehicle acceleration model and the lowest (also for the nitrogen oxides) for the negative vehicle acceleration. On average, the greatest increase in the emission intensity of pollutants and the intensity of particle number occurred for the dynamic states of the engine corresponding to positive acceleration. The conclusions from the performed investigations entitle the authors to propose a greater allowance for the exhaust emission-related criteria in the engine control algorithms.
\end{abstract}

Keywords: combustion engine; exhaust emissions; Real Driving Emissions; dynamic operating states

\section{Introduction}

The advancement in the features of combustion engines used in motor vehicles is currently determined by the following criteria [1-3]:

- environmental criteria (exhaust emissions),

- $\quad$ economy criteria (overall engine efficiency and, as a consequence, fuel consumption),

- energy criteria (usable power),

- dynamics criteria (acceleration).

The criteria of evaluation of vehicle engines such as durability and reliability are today ensured on a sufficient level, which is a result of not only a rapid advancement in the area of quality of applied materials (production and maintenance) but also in the area of technology of production of modern engines.

A great significance in the assurance of good operational properties has the advancement of the engine control systems [4]. The optimization of the control algorithms in combustion engines under static states is already sufficient [4]. The existing problems are always the dynamic states that may vary widely and the objects that are described in their dynamic states with non-linear models (sufficiently convergent with the modeled object), do not have properties independent of the states they are in [1-3]. Such complex objects are combustion engines [1-3]. 
The usable properties of combustion engines- $\mathrm{P}$ in the engine static states are functionally (function of numerical values [5]) dependent on the physical quantities describing these states-S:

$$
P=f(S)
$$

Under dynamic states this is a mathematical operator-it is described by the functional [5]:

$$
\mathrm{P}(\mathrm{t})=\Im[\mathrm{S}(\mathrm{t})]
$$

where: $\mathrm{t}$-time.

For example: the emission of a pollutant from a combustion engine under static states, at a constant vehicle velocity $-\mathrm{v}=$ const, is $-\tau$ :

$$
\mathrm{m}(\tau)=\mathrm{E} \cdot \tau
$$

where: E-pollutant emission intensity under static states dependent on the velocity in the functional form $\mathrm{E}=\mathrm{f}_{\mathrm{E}}(\mathrm{v})$.

Under dynamic states, the emission intensity for the vehicle velocity $-v(t)$ will be described by the mathematical operator:

$$
\mathrm{E}(\mathrm{t})=\Psi[\mathrm{v}(\mathrm{t})]
$$

The emission of a pollutant in time $-\tau$ is

$$
\mathrm{m}(\tau)=\int_{0}^{\tau} \mathrm{E}(\mathrm{t}) \mathrm{dt}=\int_{0}^{\tau} \Psi[\mathrm{v}(\mathrm{t})] \mathrm{dt}
$$

The emission of a pollutant under dynamic states is described as a functional of velocity, therefore it is dependent on every velocity tracing of the vehicle.

One can state that under dynamic states objects do not have inherent properties that are independent of the states they are in. The situation is even more complicated by the fact that the definiteness of the states of the objects is usually limited, which renders these processes stochastic [6]. Combustion engines in motor vehicles are such objects.

Dynamic states of combustion engines can be classified in terms of the frequency ranges of the processes, for which the values of the amplitudes of the frequency representation of the processes are significant [7]:

- slow-varying processes,

- processes related to the engine operation,

- fast-varying processes.

To the category of slow-varying processes we can assign thermal processes that characterize the engine thermal state. These processes have time constants of the order of several seconds to several minutes. The even slower-varying processes than the thermal ones are ambient conditions or the tribological processes related to the wear of the engine components.

Processes related to the engine operation are determined by its actuation. The fundamental ones are the processes of the control of the engine and its load on the side of the power takeoff. The process of engine control is understood as the action of the operator on the engine. The reaction of the vehicle is its velocity, in the case of a machine-the rate of its operation and in the case of an engine- the engine speed. The dynamic properties of these processes are characterized with a frequency range of $0.1-10 \mathrm{~Hz}$ [7].

Fast-varying processes are processes related to the engine cycle and those conditioning the occurrence of the cycle, e.g., the wave processes in the airflow through the intake system. To this group, we may also assign processes that are not always related to the cyclicity of the engine operation, yet are most frequently generated by it, e.g., engine vibration. For these processes, the characteristic frequency ranges are much greater compared to the processes related to the engine operation. 
In terms of the usable properties of engines, particularly important are their properties under the conditions of their operation. For this reason, these are operational properties: ecological, economical, energy-related, and dynamic. These properties are determined with the engine operating states described with processes characterizing the intensity of the engine operation.

In the case of vehicle combustion engines, in terms of their operational properties, it is important to investigate these properties under dynamic states determined by the conditions of actual operation.

It is, therefore, important to investigate engines under their dynamic states determined by the conditions of actual operation. For this reason, in this paper the authors attempted to investigate the exhaust emissions from a passenger vehicle operated in the RDE (Real Driving Emissions) test [8-11] (Figure 1).

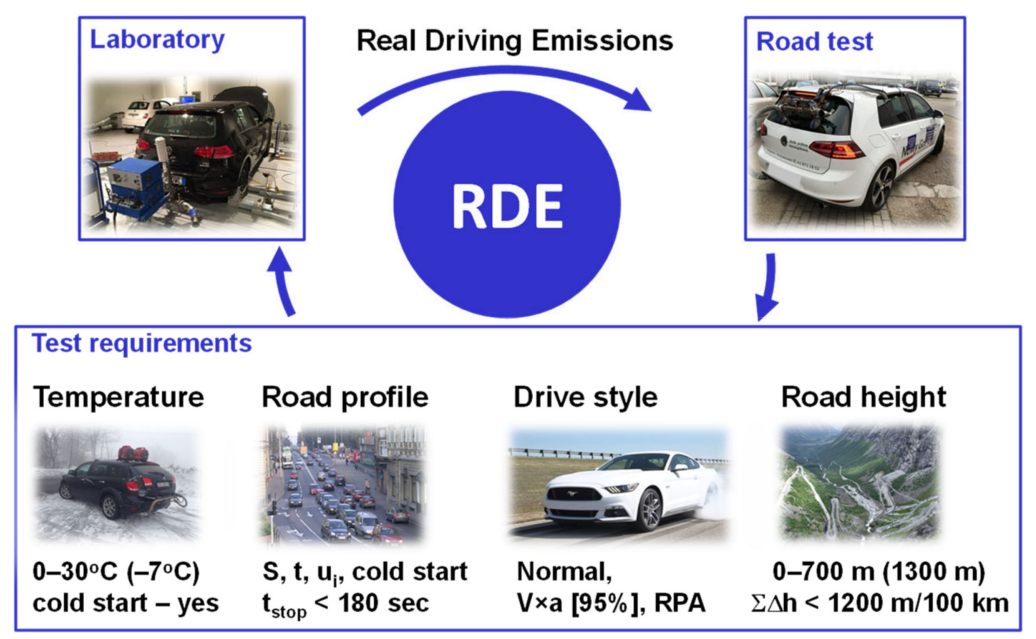

Figure 1. Formalized RDE test requirements.

The knowledge of the properties of combustion engines operating under dynamic states is not yet properly structured. This results not only from the fact that the mere diversity of the possible dynamic states is unlimited [12,13], but also from the commonplace tradition of empirical research on combustion engines. Unfortunately, the consequence of this tradition is the formal weakness of the research performed in this area, which will be discussed in the chapter devoted to the applied research methodology.

Majority of publications pertains to engine testing in research tests based on the averaged values [14-20]. Such engine are homologation test ones performed on a chassis dynamometer whose characteristic feature is that the processes of velocity and motion resistance may be deemed as determined based on the repeatability of the tests. A clear difference is observable in road tests. In such scenarios, even in the situation of reproducing a repeatable test, obstacles may appear resulting from the road traffic. This may cause the need to treat the velocity process as a stochastic one. This is particularly the case in RDE testing. In this case, only some limitations are imposed on the test realization [8-11].

As has already been mentioned, majority of the publications treating on the properties of combustion engines operating under dynamic states, determined by the velocity processes and motion resistance in the test, mainly contain the results from the entire test [14-21]. Merkisz and Pielecha [20] presented the results of investigations on the exhaust emissions from a diesel engine under actual traffic conditions. One of them was the RDE test, the other was a simulation of a homologation test performed under actual operating conditions (NEDC-New European Driving Cycle) [8]. A high sensitivity of the exhaust emissions was observed to the properties of both tests. Czerwinski et al. [16] performed a comparison of the investigation results of passenger vehicles tested with different PEMS systems on a chassis dynamometer as well as on the road. In addition, in [17], the authors presented the results of the investigations on the exhaust emissions 
from a diesel engine in the homologation procedure and in the RDE test. The highest sensitivity was observed for the emission of particulate matter: it was significantly higher in the RDE test compared to the chassis dynamometer procedure. Valverde et al. [22,23] presented the results of investigations of exhaust emissions in the aspect of the metrological characteristics of the PEMS equipment. The investigations of the exhaust emissions from non-road vehicles have also been carried out using the PEMS equipment [19].

A more analytical approach to the research on combustion engines under dynamic states has been presented in [2,18,24]. In [23], the authors presented the results of investigations of two vehicles fitted with gasoline engines in the aspect of the zero-dimensional characteristics of the velocity process, inter alia, the products of vehicle velocity and relative positive acceleration.

Kurtyka and Pielecha [18] presented the results of investigations on an engine speed under dynamic states determined with the vehicle acceleration in a specially predefined driving test simulating the actual operation of a passenger vehicle. The following was investigated: averaged emission intensity and fuel flow intensity. A significant sensitivity of the investigated processes was observed to both the dynamic states and the types of driving tests.

Chlopek and Laskowski [24] presented the pioneer methodology of determination of the road emission characteristics from a combustion engine in the domain of average speed based on the recordings of the results of the exhaust emissions intensity during a single realization of the vehicle velocity. Fragments of the recorded realizations of incidental variables such as the time of start and end of the process were treated as a stochastic process. For the determination of the characteristics, the authors used the Monte Carlo method [25].

The theory of stochastic processes was also used in the developed method of driving test synthesis based on the criterion of similarity of the spectral density [26].

In this paper, the authors proposed the investigations of the exhaust emissions from a diesel engine in the RDE test in model dynamic states. These states were defined depending on the acceleration of the vehicle.

The originality of the proposed methodology in relation to the existing knowledge found in the literature consists primarily of examining not only the averaged properties in the entire test, but also in fragments, characterized by a qualitative difference due to the vehicle dynamics. It enables the assessment of the impact the engine operating states have on its operation and use. The research methodology proposed in the article is completely original based on the existing knowledge from the literature analyzed. Thanks to the formalization of the operating states of internal combustion engines, it was possible to determine zero-dimensional characteristics of pollutant emissions in the assumed operating states. This original approach to testing vehicles in dynamic conditions enables not only a qualitative but also a quantitative assessment of the performance indicators of internal combustion engines in defined dynamic states, particularly in relation to these properties in static engine operating states, as well as the averaged properties in the entire research test.

The results of the research can be used to optimize the control algorithms of internal combustion engines with respect to the criterion of reducing exhaust emissions. For this purpose, the knowledge of the sensitivity of exhaust emissions from internal combustion engines to dynamic states can be used.

\section{Aim, Object, Program of Investigations, and Research Equipment}

The aim of the investigations is the assessment of the exhaust emissions from a diesel engine in model dynamic states in the RDE test, modeling the actual operation of a vehicle. Model dynamic states were defined depending on the vehicle acceleration.

The object of the investigations was Fiat Idea fitted with a Fiat 1.3 JTD Multijet Diesel engine. Table 1 presents the basic specifications of the test stand in the laboratory together with the engine on the dynamometer [27]. Figure 2 presents the view of the said equipment. 
Table 1. Technical specifications of the laboratory test stand.

\begin{tabular}{cc}
\hline Engine & $\begin{array}{c}1.3 \mathrm{JTD} \text { MultiJet: Diesel, } \\
\text { Direct Injection; Common Rail; R4/8v }\end{array}$ \\
\hline Engine displacement & $1248 \mathrm{~cm}^{3}$ \\
Maximum power/engine speed & $51 \mathrm{~kW} / 4000 \mathrm{rpm}$ \\
Maximum torque/engine speed & $180 \mathrm{~N} \cdot \mathrm{m} / 1750 \mathrm{rpm}$ \\
After-treatment system & Oxicat only \\
Emission generation & Euro 4 \\
\hline Dynamic dynamometer & AVL Dynoroad $120 \mathrm{~kW}$ \\
\hline Voltage & $3 \times 500 \mathrm{~V}$ \\
Frequency & $267 \mathrm{~Hz}$ \\
Power & $120 \mathrm{~kW}$ \\
Maximum torque & $509 \mathrm{~N} \cdot \mathrm{m}$ \\
Rotation speed range & $0-8000 \mathrm{rpm}$ \\
\hline
\end{tabular}

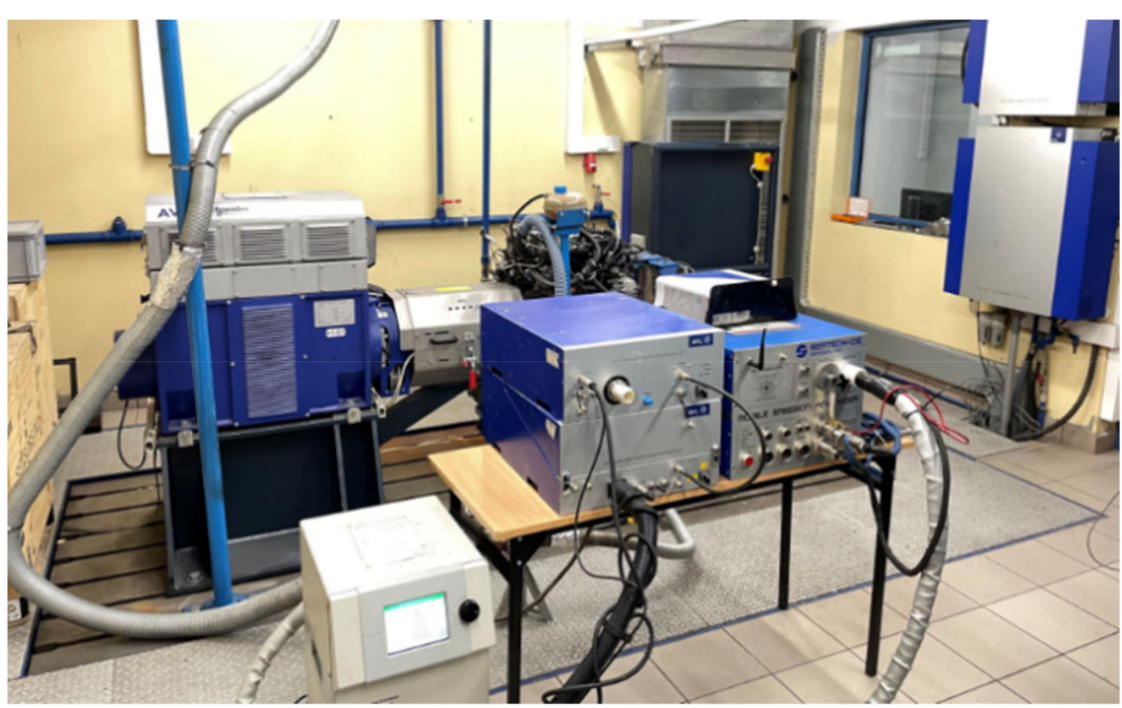

Figure 2. View of the laboratory test stand.

Tests were purposely carried out on an engine of a lower emission category (Euro 4), because of considerably greater sensitivity of exhaust emissions to dynamic states.

The program of the investigations included the realization of the RDE test in real driving conditions. The test was initiated for a warm engine (stable temperature). The following quantities were recorded throughout the tests:

- vehicle velocity,

- $\quad$ intensity of the flow of fuel consumed by the engine,

- $\quad$ exhaust emissions concentration: carbon monoxide, hydrocarbons, nitrogen oxides, and carbon dioxide,

- $\quad$ intensity of the particle number

As well as many other control quantities, indirectly used in the described investigations.

The test was carried out under urban conditions in the city of Poznan, rural conditions around the city of Poznan including an expressway portion (S11) and motorway conditions - the S11 expressway and the A2 motorway [14,26,27] (Figure 3). The total distance of the test route was approx. $75 \mathrm{~km}$. In the tests, the authors used a portable exhaust emissions analyzer (PEMS—Portable Emission Measurement System) [8-10,28]. 


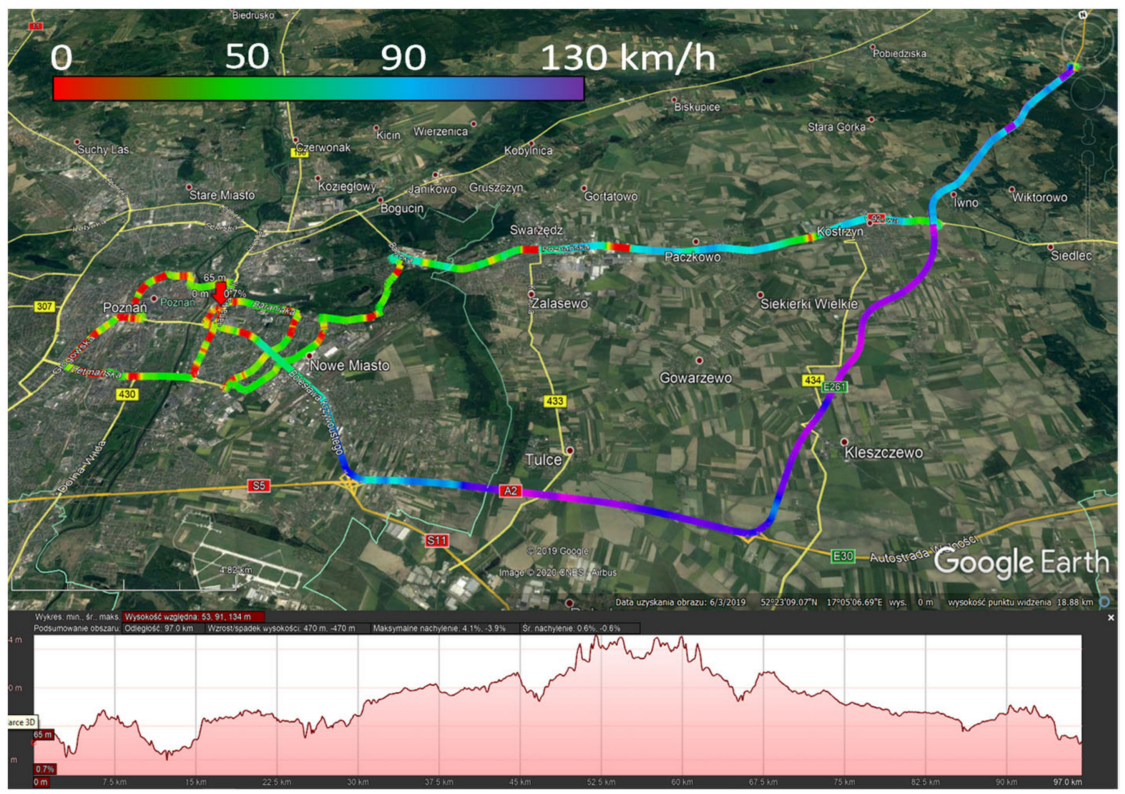

Figure 3. RDE test route visualization.

For the testing of the exhaust emissions, the authors used Semtech DS with the following modules [21]:

- the Flame Ionization Detector (FID) for the measurement of the concentration of hydrocarbons,

- the Non-Dispersive Ultraviolet (NDUV) analyzer utilizing ultraviolet radiation for the measurement of the concentration of nitrogen monoxide and nitrogen dioxide,

- the Non-Dispersive Infrared (NDIR) analyzer utilizing infrared radiation for the measurement of the concentration of carbon monoxide and carbon dioxide,

- the electrochemical analyzer for the measurement of the concentration of oxygen,

- a system for the measurement of the exhaust gas flow.

Two systems were used in parallel in this study: (1) to measure particle concentration (MSS), and (2) to measure particle number. However, the tests proved that the particle mass measurement is very insensitive to the solutions used. Therefore, it was decided to present only results related to particle number in this paper. In such tests, the EEPS 3090 Engine Exhaust Particle Sizer Spectrometer system was used together with the exhaust dilution module-Rotating Disk Thermodiluter 379020A. This configuration allowed all the necessary conditions (temperature and dilution) to be met for proper measurement of the particle number [22]. Test results from a single vehicle run in the RDE test were used for analysis. The accuracy of the exhaust emission intensity measurements and of the particle number in the RDE test complies with the normative requirements.

The quantities measured under dynamic states were recorded with the resolution of $10 \mathrm{~Hz}$ and then filtered using the second order Savitzky-Golay filter to reduce the share of noise in the high frequency signals [29].

\section{Methodology}

In general, as a process some parameters of state, which are determined in a certain normalized space $[2,3]$. The domain, in which the process is defined is most often time function, or the monotonic function of time (the process is then a function of time, otherwise referred to as the time series) or an area of space (the process is then a surface area) [2,3].

In this paper, the term "process" is understood as a function of number of values whose argument is time ( $t)$. The criterion of qualification of process $X(t)$ to static and dynamic categories is based on the derivative value of the process against time $\frac{\mathrm{dX}(\mathrm{t})}{\mathrm{dt}}$. If the 
value of the process derivative against time is 0 , the process is static. In any other case the process is dynamic.

The condition of process qualification to the category of static processes based on the zero value of the process derivative against time may be applied only in theoretical conditions. Actual processes can never meet such a condition. It is, therefore, purposeful to establish a relative criterion.

Let us adopt a relative criterion of the qualification of the process to the category of static processes:

$$
\frac{\mathrm{dX}(\mathrm{t})}{\mathrm{dt}}=\kappa \cdot R G\left[\frac{\mathrm{dX}(\mathrm{t})}{\mathrm{dt}}\right]
$$

where: $k$-parameter-real number meeting the condition: $0<\kappa \leq 1, R G\left[\frac{\mathrm{dX}(\mathrm{t})}{\mathrm{dt}}\right]$-range value operator of the process $\frac{d X(t)}{d t}[6]$ :

$$
R G\left[\frac{d X(t)}{d t}\right]=\operatorname{Max}\left[\frac{d X(t)}{d t}\right]-\operatorname{Min}\left[\frac{d X(t)}{d t}\right]
$$

where: $\operatorname{Max}\left[\frac{\mathrm{dX}(\mathrm{t})}{\mathrm{dt}}\right]-$ maximum value operator of the process $\frac{\mathrm{dX}(\mathrm{t})}{\mathrm{dt}}, \operatorname{Min}\left[\frac{\mathrm{dX}(\mathrm{t})}{\mathrm{dt}}\right]-$ minimum value operator of the process $\frac{d X(t)}{d t}$.

In engine related literature, it is incorrect to use the term "stationary" when describing dynamic or static states [30]. The term stationary is referred to the steadiness of the probabilistic characteristics of the process [30]. This term was introduced in mathematics by Andriej Markow, Sr. [30].

The engine states are described with the following processes:

- engine speed $-\mathrm{n}(\mathrm{t})$, characterizing the frequency of the realization of a thermal cycle, - torque $-\mathrm{M}_{\mathrm{e}}(\mathrm{t})$, characterizing the engine load,

- engine thermal state- $\mathrm{T}(\mathrm{t})$, defined as a set of temperatures of the engine parts and its consumables (primarily the temperature of the lubricating oil and the coolant, if the engine is cooled indirectly).

For the stabilized thermal state of the engine, its operating state is then described with processes of engine speed and torque.

In the investigations discussed in this paper, the authors utilize the relative engine torque defined with the Equation (8):

$$
\mathrm{M}_{\mathrm{er}}(\mathrm{n})=\frac{\mathrm{M}_{\mathrm{e}}(\mathrm{n})}{\mathrm{M}_{\mathrm{e} \text { ext }}(\mathrm{n})}
$$

where: $\mathrm{M}_{\mathrm{e} \text { ext }}$-torque at full throttle characteristics.

Hence, for the stabilized thermal state of the engine its operating state is theoretically static, when the following conditions are met:

$$
\frac{\mathrm{dn}(\mathrm{t})}{\mathrm{dt}}=0 ; \frac{\mathrm{dM}_{\mathrm{e}}(\mathrm{t})}{\mathrm{dt}}=0
$$

The static nature of the engine operation can also be defined in terms of the properties of the vehicle velocity process $-\mathrm{v}(\mathrm{t})$. In the paper, the authors assume that the engine states are theoretically static if the following condition is met:

$$
\frac{\mathrm{dv}(\mathrm{t})}{\mathrm{dt}}=0
$$

The derivative of the vehicle velocity against time is acceleration-a(t). In this paper, a relative criterion of the engine operating static states is assumed-as proposed (11):

$$
\mathrm{a}(\mathrm{t})<\varepsilon \cdot \operatorname{RG}[\mathrm{a}(\mathrm{t})]
$$


where: $\varepsilon$-real number meeting the condition $0<\varepsilon \leq 1$-this is the coefficient of qualification of engine states, Max-operator of the maximum value, Min-operator of the minimum value, Abs-operator of the absolute value.

Therefore, three cases are adopted:

- $\quad$ static model (11),

- positive acceleration model:

$$
a(t)>\varepsilon \cdot R G\lceil a(t)\rceil
$$

- $\quad$ negative acceleration model for:

$$
\mathrm{a}(\mathrm{t}) \leq-\varepsilon \cdot \operatorname{RG}\lceil\mathrm{a}(\mathrm{t})\rceil
$$

In the analysis, the values that are the characteristics of the following were evaluated:

- the exhaust emissions curves (carbon monoxide- $\mathrm{E}_{\mathrm{CO}}$, hydrocarbons- $\mathrm{E}_{\mathrm{HC}}$, nitrogen oxides- $\mathrm{E}_{\mathrm{NO}_{x}}$, and carbon dioxide- $\left.\mathrm{E}_{\mathrm{CO}_{2}}\right)$,

- the particle number intensity $\left(\mathrm{E}_{\mathrm{PN}}\right)$.

For the individual models, corresponding to the analyzed operating states and for the entire test the following zero-dimensional characteristics were determined:

- the extreme values-Min, Max,

- the average value- $\mathrm{AV}$,

- the standard deviation- $\mathrm{D}$,

- the coefficient of variation-W:

$$
\mathrm{W}=\frac{\mathrm{D}}{\mathrm{AV}}
$$

- the ratio of the average value of the emission intensity or the intensity of the emission of PN in the analyzed model and the average value in the entire test- $\mathrm{k}$.

\section{Research Results and Discussion}

Figure 4 presents the tracings of the vehicle velocity in the RDE test. The tracings show the following fragments: urban (up to $3794 \mathrm{~s}$ ), rural (from $3795 \mathrm{~s}$ to $4750 \mathrm{~s}$ ), motorway (from $4751 \mathrm{~s}$ ). Based on the recorded velocity tracing, the vehicle acceleration was determined. Upon differentiation of the function of velocity against time, the filtration of the course of acceleration was performed using the Savitzky-Golay filter of the second order to reduce the share of noise in the high frequency signal. The velocity graph clearly shows how the dynamic properties of the processes of velocity and acceleration significantly differ in the urban, rural, and motorway portions. No significant difference could be seen between the urban and rural portions from the curves of the vehicle velocity and acceleration, but these processes are much less dynamic in the motorway portion. The course of the vehicle velocity in the RDE test corresponds to the course of the engine speed $-n$ and the relative engine torque $-\mathrm{M}_{\mathrm{er}}$.

The difference is also significant in the nature of the process of engine speed in the urban, rural and motorway portions. In the process of torque, such a difference is not the case. The engine states of operation are determined by the engine properties.

Figure 5 present the tracings of the tailpipe emission intensity of: carbon monoxide$\mathrm{CO}$, hydrocarbons $-\mathrm{HC}$, nitrogen oxides $-\mathrm{NO}_{\mathrm{x}}$ reduced to nitrogen monoxide, carbon dioxide $-\mathrm{CO}_{2}$, and particle number- $\mathrm{PN}[2,3]$. 


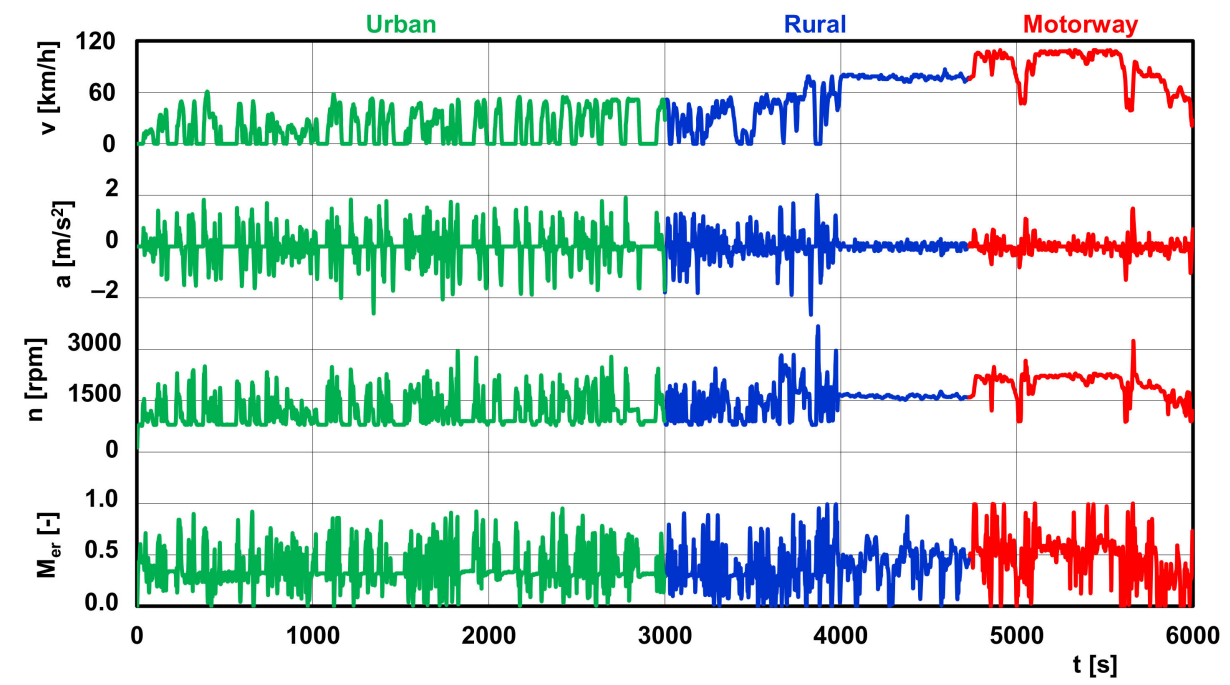

Figure 4. Vehicle velocity, vehicle acceleration, engine speed and relative engine torque as a function of time in the RDE test.

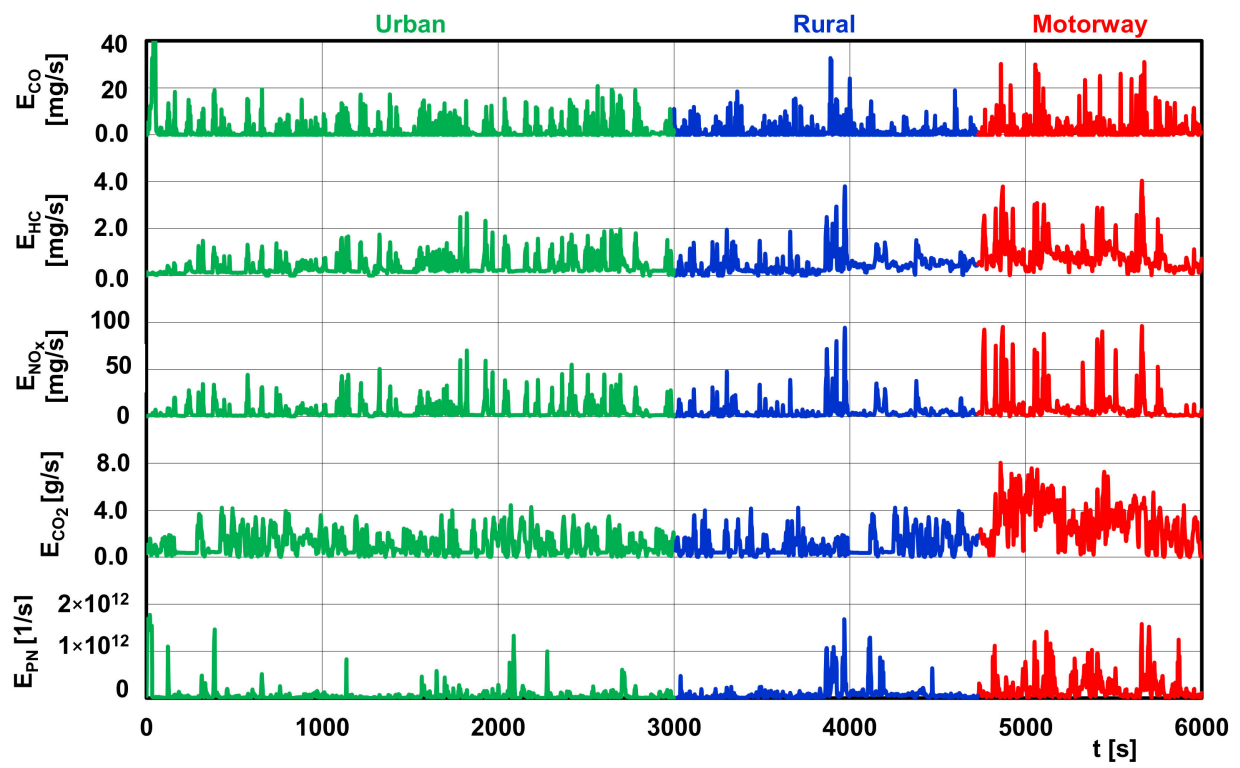

Figure 5. Carbon monoxide, hydrocarbons, nitrogen oxides, carbon dioxide, and particle number emission intensity as a function of time in the RDE test.

The zero-dimensional characteristics of the engine speed processes and relative torque (the minimum value, the maximum value, the average value, and the standard deviation) have been shown in Table 2.

Both the process of engine speed and relative engine torque are characterized by a great deal of variability. The average value for the engine speed is approx. $1445 \mathrm{~min}^{-1}$ and for the relative engine torque-approx. 0.4. The coefficient of variation is greater for the relative torque and amounts to 0.46 . For the engine speed, the coefficient of variation equals 0.35 . The processes of emission intensity of individual exhaust components and the intensity of particle number are characterized by a great deal of variability. The greatest value of the coefficient of variation is for the emission intensity of carbon monoxide and amounts to 1.815. A slightly lower coefficient of variation is for nitrogen oxides (1.741) and PN (1.600). The lowest coefficient of variation occurs for the hydrocarbons (0.971). A similar level of this coefficient has carbon dioxide (0.984). The coefficient of qualification of the engine states in Equations (3)-(5) was adopted at 0.01. 
Table 2. The zero-dimensional characteristics of the engine speed processes, relative torque and processes of exhaust emission intensity (the minimum value, the maximum value, the average value, and the standard deviation).

\begin{tabular}{ccccc}
\hline Zero-Dimensional Characteristic Concept & $\begin{array}{c}\text { Minimum } \\
\text { Value } \\
\text { (MIN) }\end{array}$ & $\begin{array}{c}\text { Maximum } \\
\text { Value } \\
\text { (MAX) }\end{array}$ & $\begin{array}{c}\text { Average } \\
\text { Value } \\
\text { (AV) }\end{array}$ & $\begin{array}{c}\text { Standard } \\
\text { Deviation } \\
\text { (D) }\end{array}$ \\
\hline $\begin{array}{c}\text { Engine speed, } \mathrm{n}[\mathrm{rpm}] \\
\text { Relative engine torque, } \mathrm{M}_{\mathrm{r}}[-]\end{array}$ & 133 & 3670 & 1445 & 507 \\
Intensity of carbon monoxide emission, $\mathrm{E}_{\mathrm{CO}}[\mathrm{mg} / \mathrm{s}]$ & 0.000 & 1.000 & 0.397 & 0.184 \\
Intensity of hydrocarbons emission, $\mathrm{E}_{\mathrm{HC}}[\mathrm{mg} / \mathrm{s}]$ & 0.017 & 50.500 & 2.290 & 4.160 \\
Intensity of nitrogen oxides emission, $\mathrm{E}_{\mathrm{NO}}[\mathrm{mg} / \mathrm{s}]$ & 0.020 & 9.050 & 0.503 & 0.489 \\
Intensity of carbon dioxide emission, $\mathrm{E}_{\mathrm{CO}}[\mathrm{g} / \mathrm{s}]$ & 0.035 & 10.600 & 6.650 & 1.610 \\
Intensity of particle number, $\mathrm{E}_{\mathrm{PN}}[1 / \mathrm{s}]$ & $4.17 \times 10^{8}$ & $2.95 \times 10^{12}$ & $1.09 \times 10^{11}$ & $1.75 \times 10^{11}$ \\
\hline
\end{tabular}

Detailed data values concerning the dimensionless characteristics of the exhaust emission intensity and of the particle number in the analyzed states of the RDE test were presented in the Table 3.

Table 3. Dimensionless characteristics of exhaust emission concentration and the particle number in the analyzed states of the RDE test: T—entire test, Min—minimum value, Max-maximum value, $\mathrm{AV}$-mean value.

\begin{tabular}{|c|c|c|c|c|c|c|}
\hline & & $\mathrm{E}_{\mathrm{CO}}$ & $\mathrm{E}_{\mathrm{HC}}$ & $\mathrm{E}_{\mathrm{NOx}}$ & $\mathrm{E}_{\mathrm{CO} 2}$ & $\mathrm{E}_{\mathbf{P N}}$ \\
\hline & & $\mathrm{mg} / \mathrm{s}$ & $\mathrm{mg} / \mathrm{s}$ & $\mathrm{mg} / \mathrm{s}$ & $\mathrm{g} / \mathrm{s}$ & $1 / \mathrm{s}$ \\
\hline \multirow{3}{*}{$\mathrm{T}$} & Min & $1.67 \times 10^{-2}$ & $1.33 \times 10^{-2}$ & $2.00 \times 10^{-2}$ & $3.53 \times 10^{-2}$ & $4.17 \times 10^{8}$ \\
\hline & Max & $5.05 \times 10^{1}$ & 4.05 & $9.63 \times 10^{-1}$ & $1.06 \times 10^{1}$ & $2.95 \times 10^{12}$ \\
\hline & $\mathrm{AV}$ & 2.60 & $5.64 \times 10^{-1}$ & 7.65 & 1.69 & $1.19 \times 10^{11}$ \\
\hline \multirow{3}{*}{$a=0$} & Min & $1.67 \times 10^{-2}$ & $1.33 \times 10^{-2}$ & $2.00 \times 10^{-2}$ & $3.53 \times 10^{-2}$ & $4.17 \times 10^{8}$ \\
\hline & Max & $3.28 \times 10^{1}$ & 2.20 & $4.70 \times 10^{1}$ & 5.32 & $2.79 \times 10^{12}$ \\
\hline & $\mathrm{AV}$ & 1.75 & $5.68 \times 10^{-1}$ & 5.14 & 2.00 & $1.10 \times 10^{11}$ \\
\hline \multirow{3}{*}{$a<0$} & Min & $1.67 \times 10^{-2}$ & $1.33 \times 10^{-2}$ & $2.00 \times 10^{-2}$ & $3.53 \times 10^{-2}$ & $4.17 \times 10^{8}$ \\
\hline & Max & $5.05 \times 10^{1}$ & 2.15 & $3.83 \times 10^{1}$ & 5.20 & $2.95 \times 10^{12}$ \\
\hline & $\mathrm{AV}$ & 1.79 & $3.16 \times 10^{-1}$ & 2.60 & $7.97 \times 10^{-1}$ & $8.13 \times 10^{10}$ \\
\hline \multirow{3}{*}{$a>0$} & Min & $1.67 \times 10^{-2}$ & $1.33 \times 10^{-2}$ & $2.00 \times 10^{-2}$ & $3.53 \times 10^{-2}$ & $4.17 \times 10^{8}$ \\
\hline & Max & $5.04 \times 10$ & 4.05 & $9.63 \times 10^{1}$ & $1.06 \times 10^{1}$ & $1.94 \times 10^{12}$ \\
\hline & $\mathrm{AV}$ & 3.98 & $8.17 \times 10^{-1}$ & $1.45 \times 10^{1}$ & 2.41 & $1.64 \times 10^{11}$ \\
\hline
\end{tabular}

Figures 6 and 7 present the zero-dimensional characteristics of the processes of vehicle velocity, acceleration and emission intensity of individual exhaust components and the particle number intensity for the models of engine operating states and for the entire test (the minimum value, the maximum value, the average value, and the standard deviation).

The values of the zero-dimensional characteristics of the process of speed for different engine operating states vary widely. The most dynamic is the process of speed in both positive and negative acceleration $(0.690$ and 0.684 .) In the steady states, the coefficient of variation is almost twice as low (0.389). The average value of the speed is the highest for the static states $(73.3 \mathrm{~km} / \mathrm{h}$, the negative acceleration states- $46.1 \mathrm{~km} / \mathrm{h}$ and the positive acceleration states- $43.5 \mathrm{~km} / \mathrm{h}$ ). The maximum absolute value of acceleration in the positive and negative acceleration models has similar values-2.01 m/s $/ \mathrm{s}^{2}$ and $2.65 \mathrm{~m} / \mathrm{s}^{2}$ respectively. The coefficient of variation is higher for the model of negative acceleration (1.01). For the positive acceleration, the coefficient of variation is 0.84 .

The highest maximum value of exhaust emission intensity is for the positive acceleration except the particle number intensity - in this case, the maximum value is the highest for the negative acceleration. The average value of the emission intensity for all the exhaust components and the particle number intensity is the highest for the positive acceleration. 
The emission characteristics found are original in terms of their dependence on model dynamic states of engine operation.

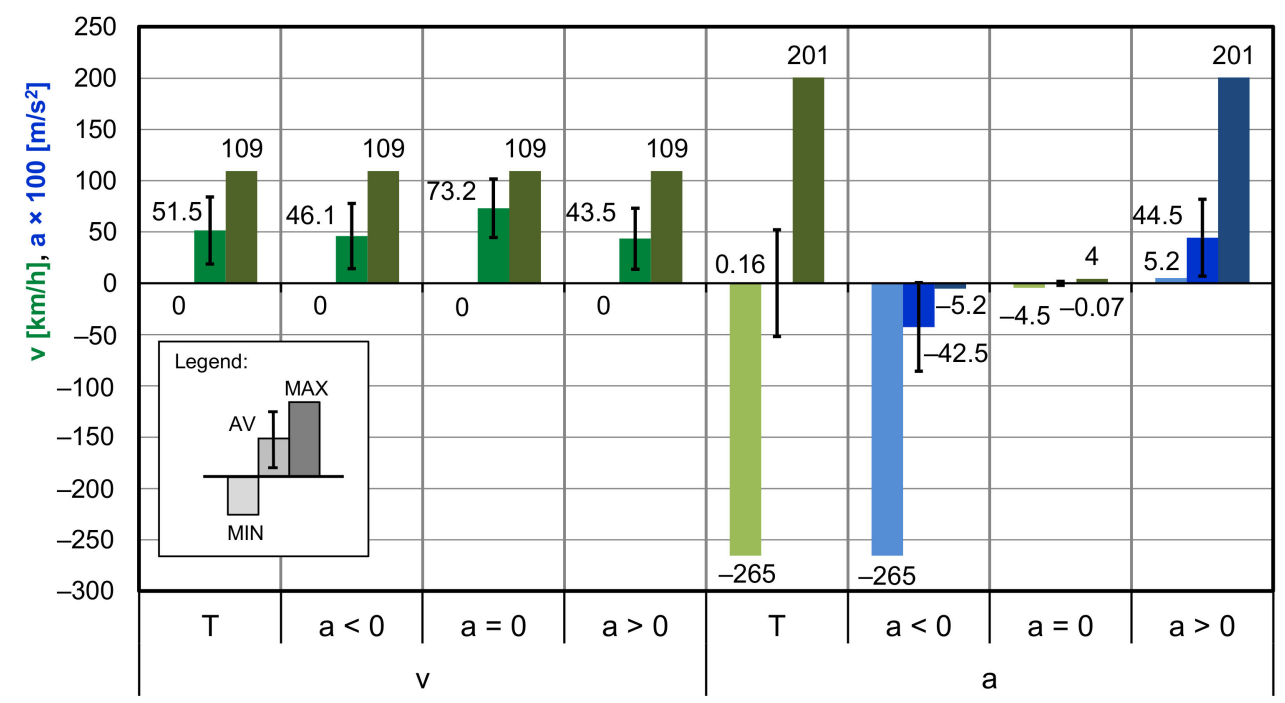

Figure 6. Zero-dimensional characteristics of the process of vehicle velocity and acceleration for the models of engine operating states and for the entire test.

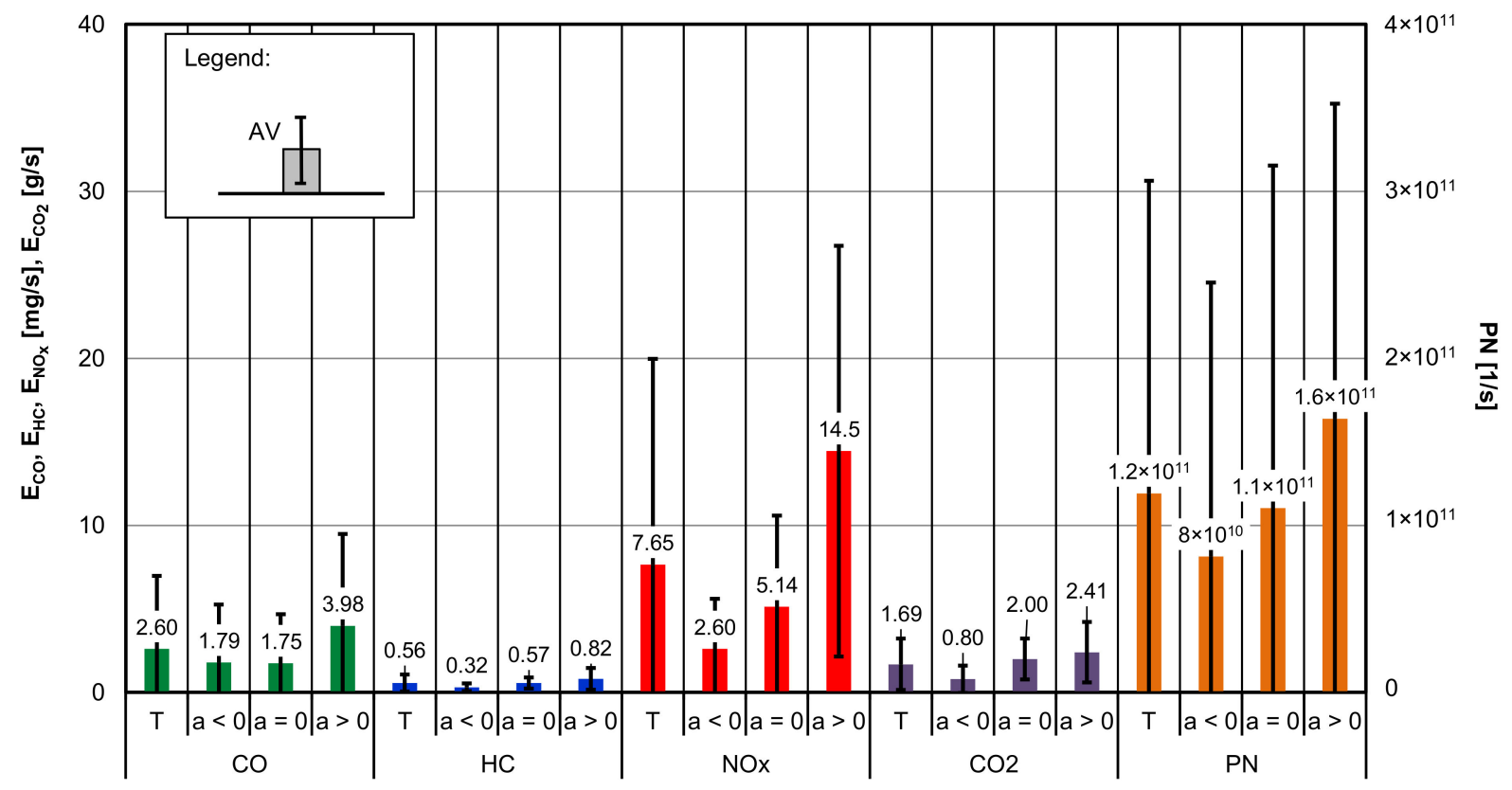

Figure 7. Zero-dimensional characteristics of the process of emission intensity of carbon monoxide, hydrocarbons, nitrogen oxides, carbon dioxide and particle number for the models of engine operating states and for the entire test.

Figure 8 presents the coefficients of variation of the processes of emission intensity of individual exhaust components and the particle number intensity for the analyzed engine operating states and for the entire test.

The highest coefficient of variation is for the particle number intensity in the model of negative acceleration. A similar value, in the same engine operating states, has the coefficient of variation of the emission intensity of carbon monoxide. On average, the lowest coefficient of variation of the emission intensity occurs in the static engine operating states for all the exhaust components except the emission intensity of carbon monoxide and particle number intensity. 


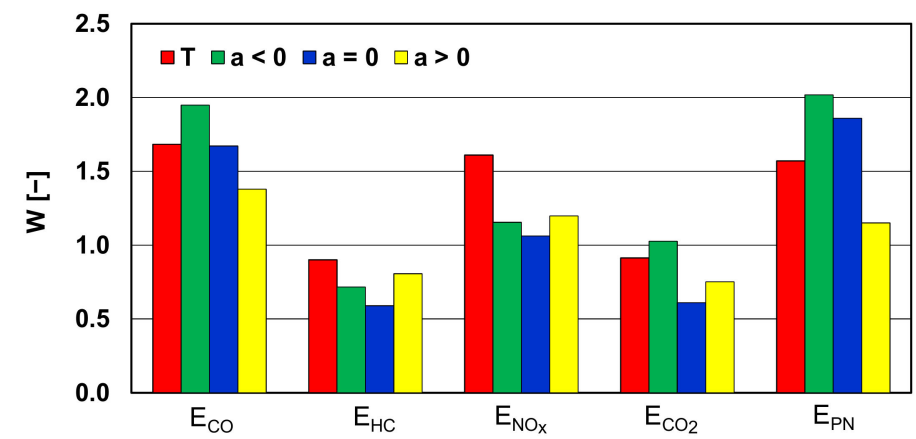

Figure 8. The coefficient of variation of the processes of emission intensity of individual exhaust components and particle number intensity for the analyzed engine operating states and for the entire test.

Figure 9 presents the ratio of the average value of the emission intensity of individual exhaust components and the particle number intensity in the analyzed model and the average value in the entire test.

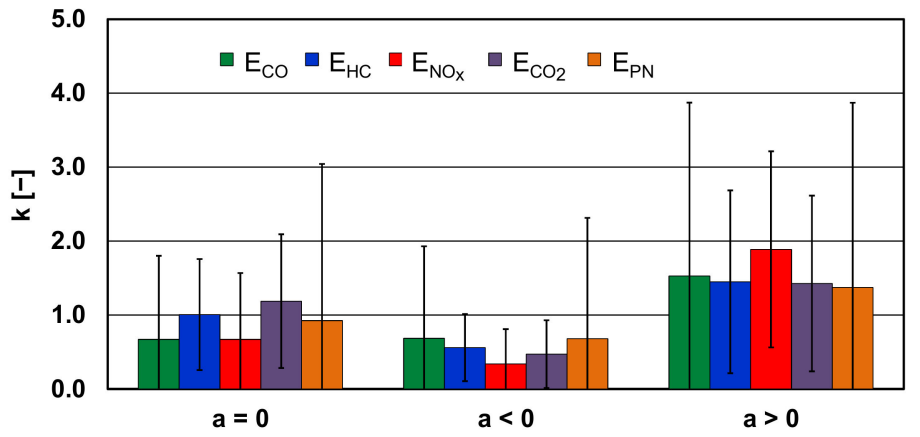

Figure 9. The ratio of the value of average emission intensity of individual components and the particle number intensity in the analyzed model and the average value in the entire test.

The greatest increase occurs for the emission intensity of nitrogen oxides in the model of positive acceleration and the smallest also occurs for the nitrogen oxides in the model of negative acceleration. On average, the greatest ratio of average emission intensity in the engine operating models and the average value thereof for the entire test is for the positive acceleration-1.534 and the smallest for the negative acceleration-0.548. In terms of the exhaust components, the average value of the ratio of average emission intensity of individual components and the emission intensity of particulate matter in the analyzed model and the average value in the entire test is similar and falls in the range 0.92-1.02.

Figure 9 also shows the total measurement uncertainties of the obtained results. It can be seen that the highest uncertainty values occurred in moments of positive acceleration and are greater than the obtained average results values. This is influenced by the obtained road emission values of the measured harmful compounds. On the other hand, the nature of the changes remains consistent with the previous results: the measurement results of carbon monoxide and particulate matter emissions are subject to the greatest uncertaintythey are more than double the obtained mean values.

The results presented in this paper are consistent with the results of the authors previous work and other publications [12,26,27]. The research results are unique as they pertain to the properties of a combustion engine in its dynamic states during an RDE test, i.e., the conditions, under which such investigations have not yet been performed.

\section{Conclusions}

Upon completing the investigations, the following conclusions have been drawn: 
1. The process of vehicle velocity in the RDE test is characterized by a great deal of variability. The dynamic properties of the vehicle velocity process are similar for the negative and positive acceleration.

2. Under the RDE conditions, the engine speed and torque processes are also characterized by a great deal of variability. Even more dynamic are the processes of intensity of emission of individual exhaust components and the emission intensity of particulate matter.

3. The highest maximum value of exhaust emission intensity is for the positive acceleration except the intensity of emission of particulate matter-in this case the maximum value is for the negative acceleration.

4. The average value of the emission intensity of all exhaust components and the intensity of the emission of particulate matter is the highest for the positive acceleration.

5. The strongest dynamic properties have the processes of emission intensity of particulate matter and carbon monoxide in the model of negative acceleration.

6. The greatest increase in the emission intensity is for nitrogen oxides in the model of positive acceleration and the smallest also for nitrogen oxides but in the model of negative acceleration.

7. On average, the greatest increase in the intensity of exhaust emissions and the emission of particulate matter is for the dynamic states of the engine operation for positive acceleration.

Conclusions formulated based on the conducted research result in postulate that criteria related to the emission of pollutants should be taken into account to a greater extent in the engine operation control algorithms. This is obviously a difficult task, because sometimes the control objectives are partially contradictory, e.g., in order to reduce the emission rate of nitrogen oxides during acceleration, the fuel dose control algorithm should limit its increase, while, due to the need to obtain high useful power, the opposite should be done.

The analyzed properties of a combustion engine in terms of exhaust emissions have been performed for schematic and averaged properties of the engine operating processes, i.e., for the engine states describing the process of vehicle velocity (steady states and positive and negative acceleration). More detailed investigations are possible in terms of the dynamic processes of engine control, engine speed, and torque, such that have been proposed in [1-3]. Due to the very large number of definable dynamic states of internal combustion engines used in cars in road tests, the set of test results would be very extensive. The presentation of the results of such investigations cannot be achieved in the form of a journal publication. It is only possible in the form of a monograph.

Author Contributions: Conceptualization, Z.C. and J.M.; methodology, Z.C.; software, J.P.; validation, M.A.-Z., J.P. and J.M.; formal analysis, Z.C.; investigation, J.P.; resources, J.M.; writing—original draft preparation, Z.C.; writing-review and editing, J.P.; visualization, J.P.; supervision, J.M.; project administration, M.A.-Z. All authors have read and agreed to the published version of the manuscript.

Funding: This research received no external funding.

Institutional Review Board Statement: Not applicable.

Informed Consent Statement: Not applicable.

Conflicts of Interest: The authors declare no conflict of interest.

\section{Nomenclature}

a vehicle acceleration

Abs absolute value operator

$\mathrm{AV}$ average value

$\mathrm{CO}$ carbon monoxide

$\mathrm{CO}_{2}$ carbon dioxide 


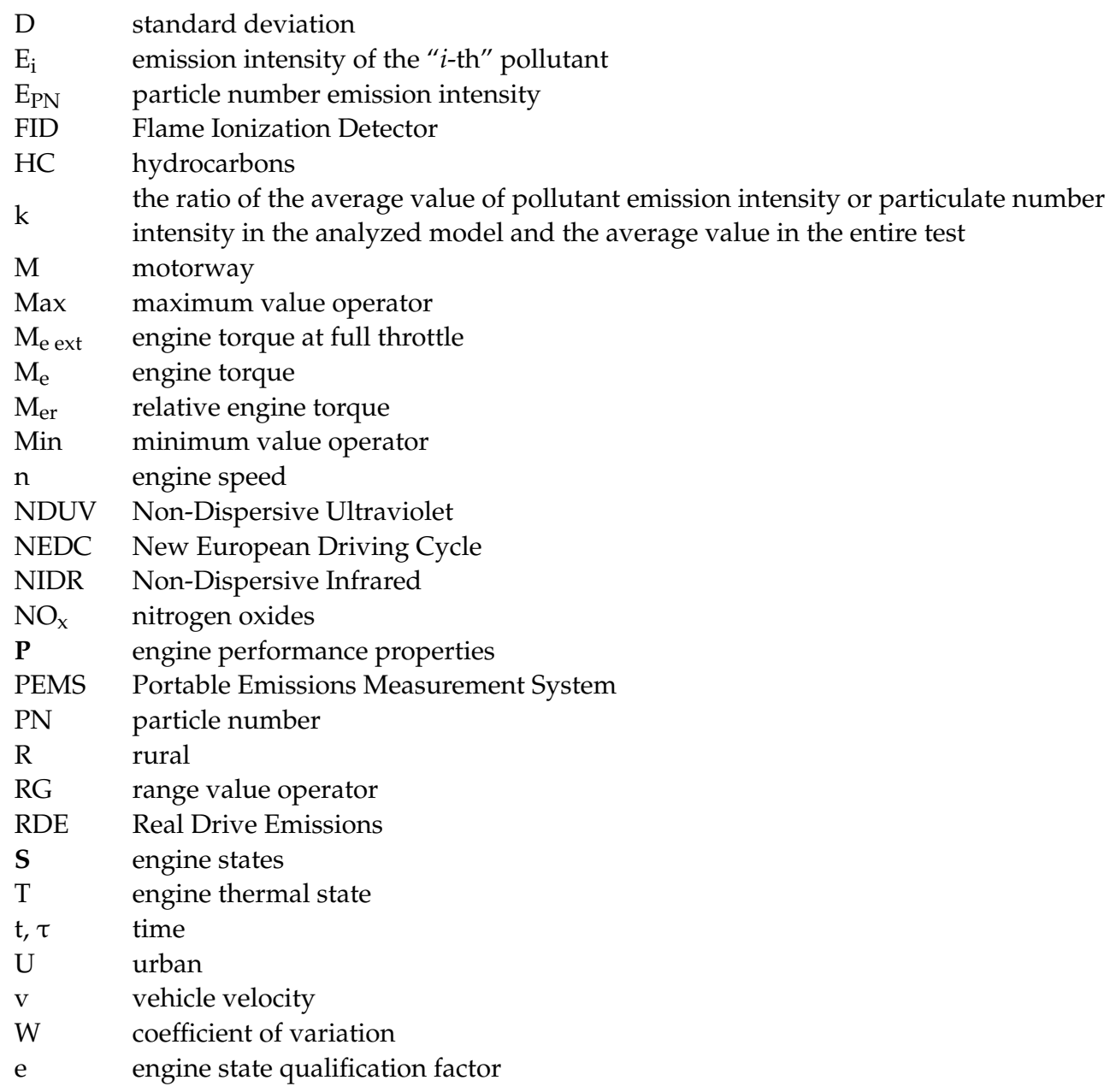

\section{References}

1. Chłopek, Z.; Biedrzycki, J.; Lasocki, J.; Wójcik, P.; Samson-Bręk, I. Modelling of motor vehicle operation for the evaluation of pollutant emission and fuel consumption. Combust. Engines 2017, 171, 156-163. [CrossRef]

2. Chłopek, Z.; Biedrzycki, J.; Lasocki, J.; Wójcik, P. Assessment of the impact of dynamic states of an internal combustion engine on its operational properties. Eksploat. Niezawodn. Maint. Reliab. 2015, 17, 35-41. [CrossRef]

3. Chłopek, Z. Some remarks on engine testing in dynamic states. Silniki Spalinowe Combust. Engines 2010, 143, 60-72. [CrossRef]

4. Guzzella, L.; Onder, C.H. Introduction to Modeling and Control of Internal Combustion Engine Systems; Springer: Berlin/Heidelberg, Germany, 2010. [CrossRef]

5. Cox, D.R.; Hinkley, D.V. Theoretical Statistics; Chapman \& Hall: London, UK, 1974.

6. Chłopek, Z. Synthesis of driving cycles in accordance with the criterion of similarity of frequency characteristics. Eksploat. Niezawodn. Maint. Reliab. 2016, 18, 572-577. [CrossRef]

7. Banach, S. Theory of Linear Operations; Elsevier: Amsterdam, The Netherlands, 1987.

8. Commission Regulation (EU) 2016/427 of 10 March 2016 Amending Regulation (EC) No. 692/2008 as Regards Emissions from Light Passenger and Commercial Vehicles (Euro 6), Verifying Real Driving Emissions. Off. J. Eur. Union 2016, 82, 1-98. Available online: http:/ / data.europa.eu/eli/reg/2016/427/oj (accessed on 16 January 2021).

9. Commission Regulation (EU) 2016/646 of 20 April 2016 amending Regulation (EC) No. 692/2008 as Regards Emissions from Light Passenger and Commercial Vehicles (Euro 6), Verifying Real Driving Emissions. Off. J. Eur. Union 2016, 109, 1-22. Available online: http:/ / data.europa.eu/eli/reg/2016/646/oj (accessed on 16 January 2021).

10. European Commission (2017) Regulation (EC) 2017/1151 of 1 June 2017 Supplementing Regulation (EC) No. $715 / 2007$ of the European Parliament and of the Council on Type-Approval of Motor Vehicles with Respect to Emissions from Light Passenger and Commercial Vehicles (Euro 5 and Euro 6) and on Access to Vehicle Repair and Maintenance Information, Amending Directive 2007/46/EC of the European Parliament and of the Council, Commission Regulation (EC) No. 692/2008 and Commission Regulation (EU) No. 1230/2012 and Repealing Commission Regulation (EC) No. 692/2008. Off. J. Eur. Union. 2017, 175, 1-643. Available online: http:/ / data.europa.eu/eli/reg/2017/1151/oj (accessed on 16 January 2021).

11. Worldwide Emission Standards. Passenger Cars and Light Duty Vehicles 2020/2021. In Innovation for the Real World; Delphi: London, UK, 2020. 
12. Merkisz, J.; Pielecha, J.; Radzimirski, S. New Trends in Emission Control in the European Union; Springer Tracts on Transportation and Traffic-STTT 4; Springer: New York, NY, USA, 2014; Volume 4.

13. Merkisz, J.; Pielecha, J. Nanoparticle Emissions from Combustion Engines; Springer Tracts on Transportation and Traffic-STTT 8; Springer: New York, NY, USA, 2015; Volume 8.

14. Andrych-Zalewska, M.; Chłopek, Z.; Merkisz, J.; Pielecha, J. Evaluation of the test drive cycle conditions impact on exhaust emissions from an internal combustion engine. Combust. Engines 2018, 175, 3-9. [CrossRef]

15. White, L.; Miles, A.; Boocock, C.; Cooper, J.G.; Mills, S. A Comparison of Real Driving Emissions from Euro 6 Diesel Passenger Cars with Zero Emission Vehicles and Their Impact on Urban Air Quality Compliance. Urban Air Quality Study: Extension I; Concawe: Brussels, Belgium, 2018.

16. Czerwinski, J.; Zimmerli, Y.; Hüssy, A.; Engelmann, D.; Bonsack, P.; Remmele, E.; Huber, G. Testing and evaluating real driving emissions with PEMS. Combust. Engines 2018, 173, 17-25. [CrossRef]

17. International Transport Forum. Real-Word Vehicle Emissions. Discussion Paper No. 2017-06. In Proceedings of the International Transport Forum, Paris, France, 2 June 2017.

18. Kurtyka, K.; Pielecha, J. The evaluation of exhaust emission in RDE tests including dynamic driving conditions. Transp. Res. Procedia 2019, 40, 338-345. [CrossRef]

19. Merkisz, J.; Lijewski, P.; Fuc, P.; Weymann, S. Exhaust emission tests from non-road vehicles conducted with the use of PEMS analyzers. Eksploat. Niezawodn. Maint. Reliab. 2013, 15, 364-368.

20. Merkisz, J.; Pielecha, J. Comparison of Real Driving Emissions Ttests; IOP Conference Series: Materials Science and Engineering; IOP Publishing: Bristol, UK, 2018; Volume 421, p. 42055. [CrossRef]

21. Semtech-DS. On Board Vehicle Emissions Analyzer. In User Manual; Document: 9510-086, Revision: 2.01; Semtech-DS: Saline, MI, USA, 2010.

22. TSI 3090 EEPS $^{\mathrm{TM}}$ (Engine Exhaust Particle Sizer ${ }^{\mathrm{TM}}$ ). User Manual; TSI: Shoreview, MN, USA, 2008.

23. Valverde, M.V.; Giechaskiel, B.; Carriero, M. Real Driving Emissions: 2018-2019 Assessment of Portable Emissions Measurement Systems (PEMS) Measurement Uncertainty; Publications Office of the European Union: Luxembourg, 2020. [CrossRef]

24. Chłopek, Z.; Laskowski, P. Pollutant emission characteristics determined using the Monte Carlo Method. Eksploat. I Niezawodn. Maint. Reliab. 2009, 2, 42-51.

25. Metropolis, N.; Ulam, S. The Monte Carlo Method. J. Am. Stat. Assoc. 1949, 247, 335-341. [CrossRef] [PubMed]

26. Andrych-Zalewska, M.; Chłopek, Z.; Merkisz, J.; Pielecha, J. Investigations of the exhaust emissions from a combustion engine under simulated actual operating conditions in the Real Driving Emissions test. Energies 2021, 14, 935. [CrossRef]

27. Andrych-Zalewska, M.; Chłopek, Z.; Merkisz, J.; Pielecha, J. Exhaust emission from a vehicle engine operating in dynamic states and conditions corresponding to real driving. Combust. Engines 2019, 178, 99-105. [CrossRef]

28. Commission Regulation (EC) 715/2007 of the European Parliament and of the Council of 20 June 2007 on Type Approval of Motor Vehicles with Respect to Emissions from Light Passenger and Commercial Vehicles (Euro 5 and Euro 6) and on Access to Vehicle Repair and Maintenance Information, European Commission (EC). Off. J. Eur. Union 2007, 171, 1-16. Available online: http:/ / data.europa.eu/eli/reg/2007/715/oj (accessed on 10 January 2021).

29. Savitzky, A.; Golay, M.J.E. Smoothing and differentiation of data by simplified least squares procedures. Anal. Chem. 1964, 36, 1627-1639. [CrossRef]

30. Papoulis, A.; Pillai, S.U. Probability, Random Variables, and Stochastic Processes; McGraw-Hill Book Co.: New York, NY, USA, 1965. [CrossRef] 